\title{
GERMINAÇÃo DE SEMENTES DE Parkia pendula (Willd.) Benth. ex Walp. (FABACEAE) EM DIFERENTES TEMPERATURAS ${ }^{1}$
}

Jociane Rosseto ${ }^{2}$, Maria Cristina de Figueiredo e Albuquerque ${ }^{3}$, Rubens Marques Rondon Neto ${ }^{4}$ e Ivan Cleiton de Oliveira Silva ${ }^{4}$

\begin{abstract}
RESUMO - Parkia pendula (Willd.) Benth. ex Walp. é uma espécie arbórea da Amazônia brasileira, pertencente à família Fabaceae, de importância regional, porém pouco conhecida, considerando-se as informações técnicas, mas muito explorada comercialmente. O objetivo deste trabalho foi avaliar a germinação das sementes em diferentes temperaturas. As sementes foram submetidas às temperaturas constantes de 15, 20, 25, 30, $35 \mathrm{e}$ $40{ }^{\circ} \mathrm{C}$ com quatro repetições de 25 sementes, colocadas para germinar em papel-toalha, na forma de rolo, mantidos em sacos plásticos transparentes em câmara de germinação sob fotoperíodo de $8 \mathrm{~h}$. Foi utilizado o delineamento inteiramente casualizado com seis tratamentos e quatro repetições. A germinação foi avaliada durante sete dias, sendo consideradas germinadas as sementes que emitiram raízes maiores que $5 \mathrm{~mm}$ e as que formaram plântulas normais. Analisaram-se as seguintes características: germinação (\%), tempo médio de germinação e formação de plântulas normais, comprimento e massa seca de plântulas. Verificou-se que as sementes de Parkia pendula germinaram em todas as temperaturas estudadas. Entretanto, a formação de plântulas foi inibida nas temperaturas de 15,20 e $40{ }^{\circ} \mathrm{C}$. A temperatura de $30^{\circ} \mathrm{C}$ foi considerada a mais favorável para a germinação e formação de plântulas dessa espécie.
\end{abstract}

Palavras-chave: Sementes florestais, análise de sementes e viabilidade.

\section{GERMINATION OF Parkia pendula (Willd.) Benth. ex Walp. (FABACEAE) SEEDS IN DIFFERENT TEMPERATURES}

\begin{abstract}
The Parkia pendula (Willd.) Benth. ex Walp. is a forest species of the Brazilian Amazon, belonging to the Fabaceae family, of regional importance. However, little is known about its species, despite its common commercial use. The objective of this work was to evaluate the germination of seeds in different temperatures. Temperatures of $15,20,25,30,35$ and $40^{\circ} \mathrm{C}$ were utilized. The six treatments were completely randomized, with four repetitions of 25 seeds kept in paper towel to germinate and kept in transparent plastic bags in a germination chamber with photoperiod of eight hours. The method used was completely randomized with six treatments and four repetitions. Germination was evaluated during seven days, being considered germinated the seeds that had emitted normal, larger than $5 \mathrm{~mm}$ roots and that, at the same time, led to seedling formation. The following characteristics were analyzed: germination (\%), average time for germination and normal formation of seedlings, seedling height and seedling dry matter. It was verified that the seeds of Parkia pendula can germinate at the temperatures of $15,20,25,30,35$ and $40^{\circ} \mathrm{C}$; however, temperatures of 15,20 and $40{ }^{\circ} \mathrm{C}$ reduced the number of seedlings. At $30{ }^{\circ} \mathrm{C}$, germination and number of seedlings of this species were maximized..
\end{abstract}

Keywords: Forest seeds, seed analysis and viability.

\footnotetext{
${ }^{1}$ Recebido em 31.08.2007 e aceito para publicação em 26.01.2009.

${ }^{2}$ Programa de Pós-Graduação em Agricultura Tropical da Universidade Federal de Mato Grosso (UFMT). E-mail: <jorosseto@ hotmail.com>.

${ }_{3}^{3}$ Departamento de Fitotecnia e Fitossanidade da UFMT. E-mail: <mariacfa@ terra.com.br>.

${ }^{4}$ Departamento de Engenharia Florestal da UFMT. E-mail: <rubensrondon@ yahoo.com.br>.
} 


\section{INTRODUÇÃO}

A germinação é um fenômeno fisiológico que se inicia com a entrada de água na semente e termina com o início do alongamento do eixo embrionário, a radícula (SOUSA-SILVA et al., 2001). Esse processo é influenciado pelas condições de umidade, temperatura, substrato, luz e ausência de patógenos (SCHMIDT, 2000). Os efeitos da luz, temperatura e umidade são os que mais o influenciam, podendo atuar sozinhos ou interagir com os demais.

A temperatura em que ocorre a germinação é um fator que tem importante influência sobre esse processo, tanto no aspecto de germinação total como na velocidade de germinação, pois a temperatura tende a influenciar agindo sobre a velocidade de absorção de água e sobre as reações bioquímicas determinantes no processo (CARVALHO e NAKAGAWA, 2000). As variações da temperatura afetam a velocidade, a porcentagem e a uniformidade da germinação (MARCOS FILHO, 2005). Esse autor também citou que a rapidez da germinação é determinada principalmente pela velocidade de embebição. Assim, é desejável a menor exposição possível das sementes a condições menos favoráveis do ambiente.

As sementes apresentam comportamento variável em função da temperatura, não havendo uma ótima para todas as espécies (BORGES e RENA, 1993), podendo estar associada às características ecológicas de cada espécie (SOUSA-SILVA et al., 2001). A germinação acontece dentro de determinados limites de temperatura. Acima ou abaixo dos limites superior e inferior, a germinação não ocorrerá (CARVALHO e NAKAGAWA, 2000), podendo acontecer a morte das sementes (BORGES e RENA, 1993).

A temperatura ou faixas de temperaturas ideais são aquelas em que ocorre máxima eficiência, obtendose o máximo de germinação no menor espaço de tempo possível (CARVALHO e NAKAGAWA, 2000). Considerase temperatura ótima aquela que possibilita a combinação mais eficiente entre a porcentageme a velocidade de germinação (MARCOS FILHO, 2005). As temperaturas máximas situamse entre 35 e $40^{\circ} \mathrm{C}$, e as mínimas geralmente são inferiores a $15^{\circ} \mathrm{C}$ (MARCOS FILHO, 2005).

A faixa de 20 a $30{ }^{\circ} \mathrm{C}$ mostra-se adequada para a germinação de grande número de espécies subtropicais e tropicais (BORGES e RENA, 1993; SCHMIDT, 2000).
Algumas espécies apresentam limites mais amplos devido a exigências distintas (MARCOS FILHO, 2005), como a maioria das espécies pioneiras que têm um nível de tolerância maior à temperatura do que as clímax (SCHMIDT, 2000).

Em sementes de espécies arbóreas, observam-se melhores desempenhos germinativos a $30^{\circ} \mathrm{C} \mathrm{em} \mathrm{sementes}$ de Ceiba pentranda (VARELA et al., 1999), de Parkia platycephala (NASCIMENTO et al., 2003), de Tabebuia impetiginosa (OLIVEIRA et al., 2005) e de Caesalpinia ferrea (LIMA et al., 2006). Em sementes de Borojoa sorbilis, Braga et al. (1999) verificaram que não ocorreram diferenças significativas na germinação, nas temperaturas de 20,30 e $35^{\circ} \mathrm{C}$ e na faixa de 30 a $35^{\circ} \mathrm{C}$.

Em sementes de Acacia polyphylla (acácia), a temperatura constante de $25^{\circ} \mathrm{C}$ foi a mais adequada para germinação (ARAÚJO NETO et al., 2003). Silva et al. (2002) verificaram que, em sementes de Myracrodruon urundeuva (aroeira), a germinação ótima ocorreu na faixa de $20 \mathrm{a} 30^{\circ} \mathrm{C}$. Lima et al. (1997), avaliando a germinação de Enterolobium contortisiliquum em temperaturas que variaram de 5 a $45^{\circ} \mathrm{C}$ (escalas de $5^{\circ} \mathrm{C}$ ), constataram melhores resultados na faixa de 18,2 a $38,8^{\circ} \mathrm{C}$. Acima de $38,8^{\circ} \mathrm{C}$ até $45^{\circ} \mathrm{C}$, houve decréscimo significativo na germinação, chegando a $0 \%$, e de 5 a $10{ }^{\circ} \mathrm{C}$ não ocorreu germinação. Araújo Neto et al. (2002) verificaram que as sementes de Guazuma ulmifolia (mutamba) não germinaram nas temperaturas de $40 \mathrm{e}$ $45^{\circ} \mathrm{C}$ e que a temperatura máxima para a germinação das sementes dessa espécie situa-se entre 35 e $40^{\circ} \mathrm{C}$.

Entre inúmeras espécies florestais de potencial econômico, encontra-se Parkia pendula (Willd.) Benth. ex Walp., popularmente conhecida como angelim-saia, pertencente à família Fabaceae. Tem ocorrência natural nos Estados do Pará, Amazonas, Acre, Mato Grosso, Rondônia e Maranhão (SOUZA et al., 1997), sul da Bahia e norte do Espírito Santo, na floresta fluvial (LORENZI, 2000). Sua madeira tem características físicas e mecânicas favoráveis para uso comercial, promovendo alto índice de exploração da espécie, o que diminui consideravelmente os exemplares em sua área de ocorrência natural.

É amplamente usada na construção civil, embarcações, móveis, artigos domésticos e decorativos (SOUZA et al., 1997), taboados, caixotaria, lâminas para compensados e canoas (LOUREIRO et al., 2000). Segundo Lorenzi (2000), pode ser empregada com sucesso no 
paisagismo para arborização de praças públicas, parques e principalmente para plantio em áreas degradadas de preservação permanente, devido ao seu rápido crescimento em ambientes abertos. O único inconveniente na introdução dessa espécie para ornamentação é o odor que as flores exalam e a resina que exsuda dos frutos (LOUREIRO et al., 2000).

Atualmente, é importante que informações sobre as condições de temperatura adequadas para a condução de teste de germinação estejam também disponíveis para um maior número de espécies florestais, visto o aumento da demanda de sua comercialização. Este estudo teve como objetivo avaliar a germinação de sementes de Parkia pendula em diferentes temperaturas.

\section{MATERIAL E MÉTODOS}

As sementes de Parkia pendula (Willd.) Benth. ex Walp, angelim-saia, foram adquiridas da organização não-governamental GAPA, situada no Município de Cláudia, norte do Estado de Mato Grosso, colhidas no mês de outubro/2004. As sementes, no momento da aquisição, estavam beneficiadas e, posteriormente, ficaram acondicionadas em garrafa plástica do tipo "pet" e armazenadas em câmara refrigerada (temperatura de $17 \pm 2{ }^{\circ} \mathrm{C}$ e umidade relativa do ar de $74 \pm 5 \%$ ) no Laboratório de Análise de Sementes da Faculdade de Agronomia e Medicina Veterinária - FAMEV da Universidade Federal de Mato Grosso - UFMT, por sete meses, quando se iniciou o experimento.

A assepsia das sementes foi realizada mediante a imersão em solução de hipoclorito de sódio $2 \%$ por 2 min e, depois, lavadas com água destilada. As sementes foram escarificadas manualmente com lixa número 100 na região oposta ao hilo, para superar a dormência tegumentar (BARBOSA et al., 1984).

As sementes foram colocadas para germinar em substrato de papel toalha, na forma de rolo, previamente umedecido com água destilada na quantidade de 2,5 vezes a massa do papel seco. Os rolos de papel foram mantidos dentro de sacos plásticos transparentes para conservação da umidade e colocados em câmaras de germinação nas temperaturas de 15, 20, 25, 30, 35 e $40{ }^{\circ} \mathrm{C}$ e fotoperíodo de $8 \mathrm{~h}$. Foram utilizadas quatro repetições com 25 sementes em cada tratamento. Quando necessário, foi feito o umedecimento do papel com água destilada.
A germinação das sementes foi avaliada diariamente durante sete dias, verificando-se as sementes que emitiram raiz maior que $5 \mathrm{~mm}$ e as que formaram plântulas normais, seguindo os critérios de Brasil (1992). Ao final do teste foram calculadas as porcentagens de germinação (sementes com emissão de raiz), de plântulas normais, de plântulas anormais e de sementes deterioradas, o tempo médio de germinação e de formação de plântulas normais, o comprimento de raiz e de parte aérea e massa seca de plântulas.

O tempo médio de germinação e de formação de plântulas normais foi realizado conjuntamente com o teste de germinação, a partir do dia em que surgiram as primeiras raízes e plântulas até o dia da última contagem. A fórmula empregada foi a sugerida por Edmond e Drapala (1958) apud Nakagawa (1999). Para medição do comprimento, foram utilizadas todas as plântulas normais provenientes do teste de germinação. O comprimento da raiz principal e da parte aérea foi mensurado com régua milimetrada, após a remoção dos cotilédones.

Para massa seca, utilizaram-se as plântulas provenientes do comprimento da parte aérea e radicular, colocadas em sacos de papel do tipo Kraft, devidamente identificados por tratamento e repetição, sendo 10 plântulas escolhidas aleatoriamente, por saco, e depois levadas à secagem em estufa com circulação forçada de ar à temperatura de $80^{\circ} \mathrm{C}$, por $24 \mathrm{~h}$ (NAKAGAWA, 1999). Após esse período, o material foi pesado e o resultado, expresso em gramas.

O delineamento utilizado foi o inteiramente casualizado, com seis tratamentos $(15,20,25,30,35$ e $40^{\circ} \mathrm{C}$ ) e quatro repetições de 25 sementes, e as médias foram comparadas pelo teste de Scott e Knott a 5\% de probabilidade. As análises estatísticas foram realizadas com os dados originais, pois atenderam às pressuposições da homogeneidade de variâncias e da normalidade dos resíduos.

\section{RESULTADOS E DISCUSSÃO}

A temperatura influenciou o desempenho germinativo de sementes de Parkia pendula (Tabela 1). Verifica-se, nesse Tabela, que a germinação (emissão de raiz) ocorreu em todos os tratamentos, mas a formação de plântulas normais se deu somente nas temperaturas de 25,30 e $35^{\circ} \mathrm{C}$.

R. Árvore, Viçosa-MG, v.33, n.1, p.47-55, 2009 
Tabela 1 - Germinação (\%) (G) de plântulas normais (PN) e anormais (PA) e de sementes deterioradas (SD) de Parkia pendula, em diferentes temperaturas Table 1-Germination (\%)(G), normal seedlings (PN), abnormal (PA) and spoiled seeds (SD) at different temperatures

\begin{tabular}{ccccc}
\hline Temperaturas $\left({ }^{\circ} \mathrm{C}\right)$ & $\mathrm{G}$ & $\mathrm{PN}$ & $\mathrm{PA}^{1}$ & $\mathrm{SD}^{1}$ \\
\hline 15 & $36 \mathrm{C}$ & $0 \mathrm{~B}$ & 100 & 0 \\
20 & $99 \mathrm{~A}$ & $0 \mathrm{~B}$ & 100 & 0 \\
25 & $100 \mathrm{~A}$ & $99 \mathrm{~A}$ & 1 & 0 \\
30 & $100 \mathrm{~A}$ & $99 \mathrm{~A}$ & 1 & 0 \\
35 & $96 \mathrm{~A}$ & $96 \mathrm{~A}$ & 2 & 2 \\
40 & $90 \mathrm{~B}$ & $0 \mathrm{~B}$ & 100 & 0 \\
\hline $\mathrm{CV} \%$ & 5,58 & 4,63 & & \\
\hline
\end{tabular}

Médias seguidas da mesma letra maiúscula na coluna não diferem entre si , pelo teste de Scott e Knott a 5\% de probabilidade. Os valores de plântulas anormais e sementes deterioradas não foram analisados estatisticamente ${ }^{1}$.

Mesmo com a ocorrência de germinação de sementes em todas as temperaturas, os maiores percentuais foram estatisticamente equivalentes nas temperaturas de 20 , $25,30,35^{\circ} \mathrm{C}$. Entretanto, a formação de plântulas normais somente ocorreu a 25,30 e $35^{\circ} \mathrm{C}$, pois as temperaturas de 15,20 e $40^{\circ} \mathrm{C}$ inibiram o desenvolvimento subsequente de plântulas normais. Isso demonstra que as sementes de Parkia pendula são sensíveis à variação de temperatura e a germinação de sementes e formação de plântulas normais é favorecida entre 25 e $35^{\circ} \mathrm{C}$, com porcentagens acima de $95 \%$.

Para Miranda e Ferraz (1999), a formação de plântulas normais é critério fundamental e deve ser considerado na determinação da temperatura ótima de germinação de espécies florestais, pois as exigências para o desenvolvimento pós-emergência da raiz podem mudar, de acordo com o desenvolvimento das diversas partes da plântula.

A $40^{\circ} \mathrm{C}$ ocorreu decréscimo na germinação e $100 \%$ das plântulas formadas foram anormais. A elevação da temperatura prejudicou a germinação e inibiu o desenvolvimento das plântulas (Figura 2). Toledo e Marcos Filho (1977) afirmaram que, em temperaturas acima da máxima tolerável para a germinação, ocorre a morte da semente, em geral, pela coagulação de enzimas e de outras proteínas pela ação do calor.

$\mathrm{Na}$ temperatura de $20^{\circ} \mathrm{C}$, a porcentagem de germinação foi estatisticamente equivalente à verificada em 25,30 e $35{ }^{\circ} \mathrm{C}$, porém houve inibição no desenvolvimento de plântulas normais a $20^{\circ} \mathrm{C}$. A mesma inibição foi verificada a $15^{\circ} \mathrm{C}$, entretanto o valor obtido nessa germinação diferiu estatisticamente das demais temperaturas. Em ambos os casos, após o teste as sementes oriundas desses tratamentos foram levadas à câmara de germinação a $30^{\circ} \mathrm{C}$. As que estavam a 15 e $20^{\circ} \mathrm{C}$ completaram seu desenvolvimento em três dias após a mudança de temperatura. Nas sementes que estavam a $15^{\circ} \mathrm{C}$, a germinação e formação de plântulas foram de $99 \%$, com tempo médio de 7,3 dias para a germinação e 9,9 dias para a formação de plântulas, quando colocadas a $30^{\circ} \mathrm{C}$. Nas que estavam a $20^{\circ} \mathrm{C}$, a germinação foi de $100 \%$, a formação de plântulas normais $99 \%$ e o tempo médio 3,3 e 8,3 dias, respectivamente.

Na Figura 1 estão as porcentagens acumuladas de germinação de sementes e de plântulas normais durante sete dias, nas temperaturas de 15, 20, 25, 30, 35 e $40^{\circ} \mathrm{C}$. Nas temperaturas de 15 e $20^{\circ} \mathrm{C}$, a germinação foi mais lenta, iniciando-se no sexto e terceiro dias após a semeadura e atingindo, ao final do sétimo dia, $36 \%$ e $99 \%$, respectivamente. Nessas temperaturas não houve formação de plântulas.

A $25^{\circ} \mathrm{C}$, a germinação ocorreu mais cedo, no segundo dia após a semeadura, com $22 \%$ de sementes germinadas, e esta porcentagem chegou a $100 \%$ no quarto dia após a semeadura. A formação da plântula iniciou no quarto dia depois da semeadura, com 5\%, e atingiu $99 \%$ no sexto dia. Na temperatura de $30^{\circ} \mathrm{C}$, a germinação iniciou no segundo dia após a semeadura com $60 \%$ das sementes germinadas, porém a $35^{\circ} \mathrm{C}$ a germinação, nesse mesmo período, atingiu $80 \%$. Entretanto, a porcentagem de plântulas normais foi superior na temperatura de 30 ${ }^{\circ} \mathrm{C}(99 \%)$ do que a $35^{\circ} \mathrm{C}(96 \%)$.

A $40{ }^{\circ} \mathrm{C}$, o processo germinativo iniciou no terceiro dia, com $86 \%$ de sementes germinadas, mas não ocorreu emergência de plântulas que tiveram inibição de seu desenvolvimento (Figura 2).

Esses resultados evidenciaram que as temperaturas de 25,30 e $35^{\circ} \mathrm{C}$ aceleram o processo germinativo e o tornaram mais uniforme, além de terem aumentado a porcentagem de plântulas normais. Tal fato confirma a afirmação de Carvalho e Nakagawa (2000) de que, na germinação das sementes, o fator temperatura afeta o processo germinativo de três maneiras distintas: sobre o total de germinação, sobre a velocidade de germinação e sobre a uniformidade da germinação. 

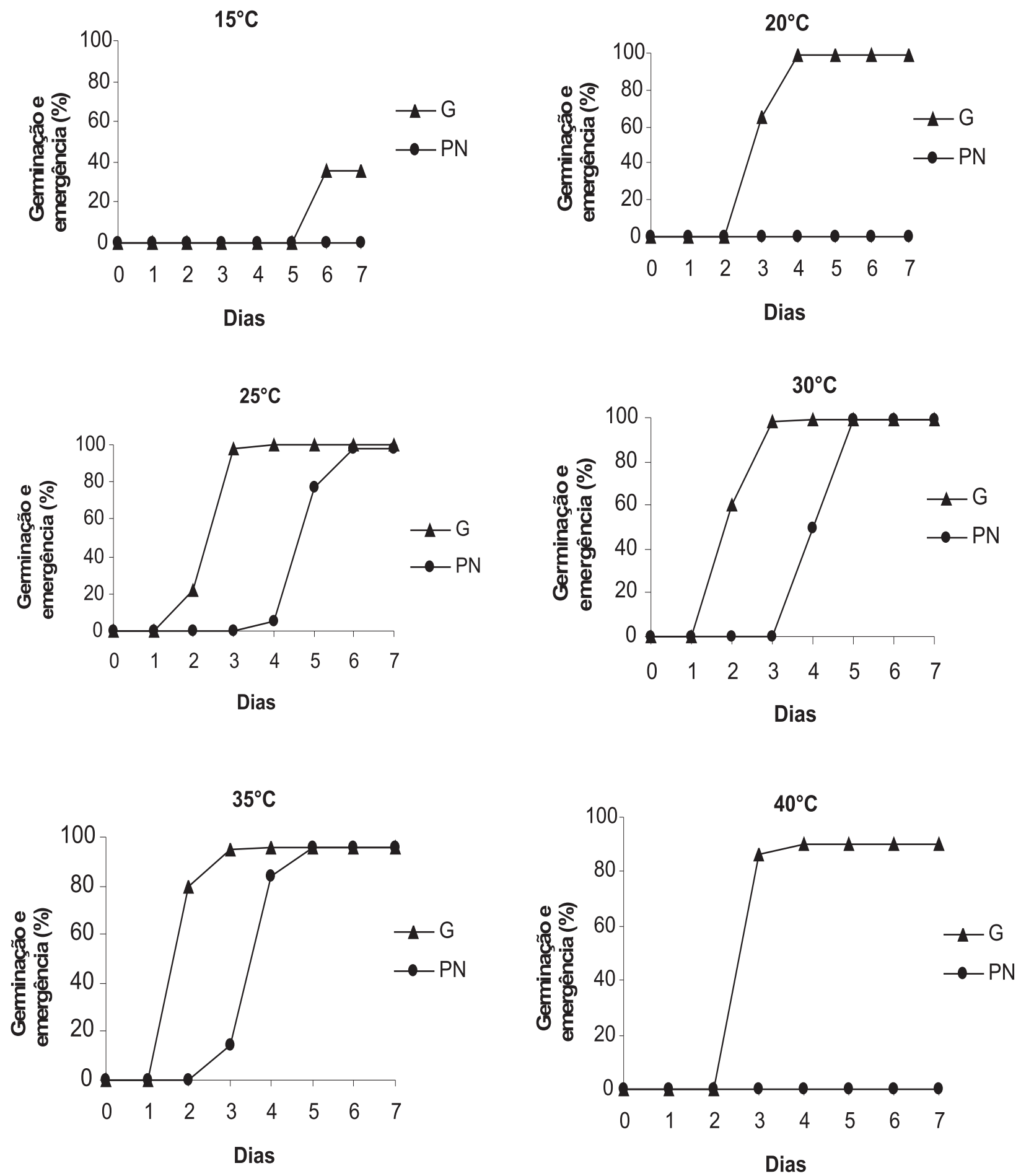

Figura 1 - Germinação acumulada de sementes (G) e formação de plântulas normais (PN) de Parkia pendula, em função do tempo.

Figure 1 -Accumulated seed germination $(G)$ and normal seedling formation (PN) of Parkia Pendula in function of time. 


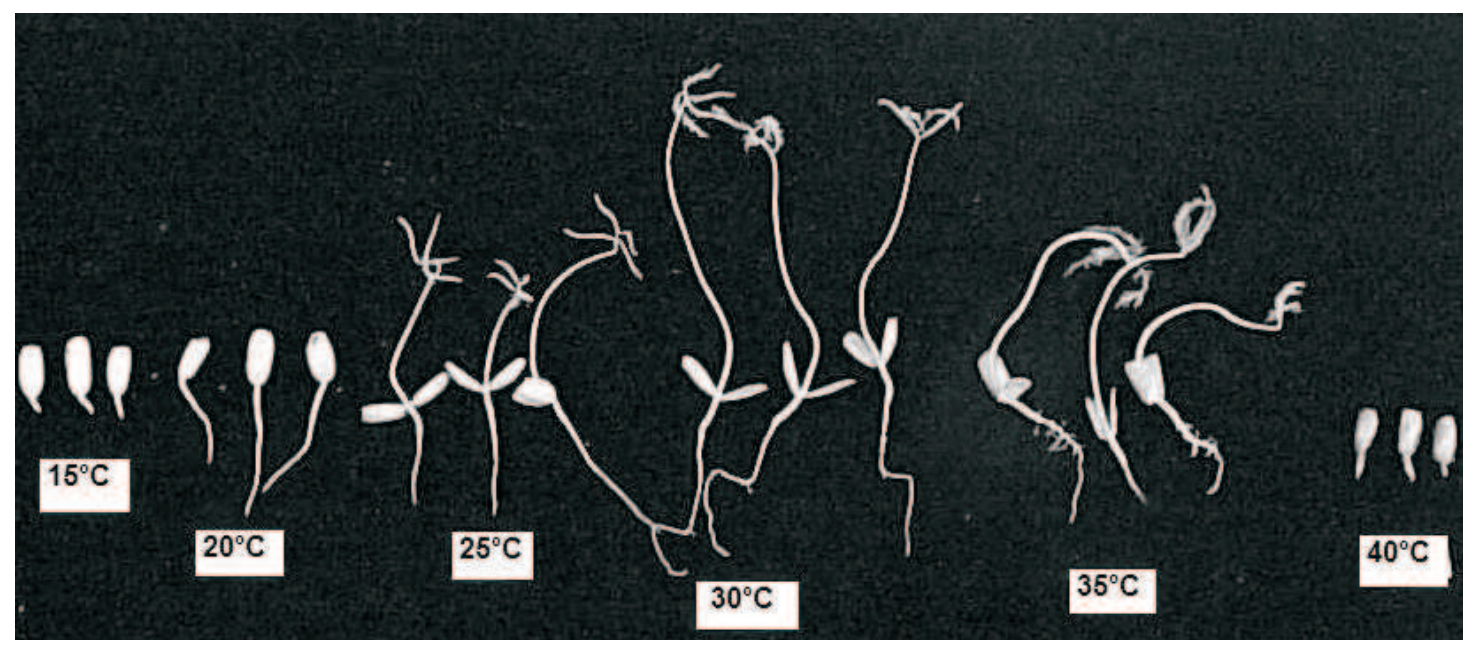

Figura 2 - Germinação de sementes de Parkia pendula em diferentes temperaturas, após sete dias de permanência na câmara de germinação.

Figure 2 - Germination of Parkia pendula seeds at different temperatures after seven day of permanence in the germination chamber.

Espécies florestais amazônicas tendem a requerer temperaturas superiores a $20^{\circ} \mathrm{C}$ para germinação, pois a temperatura média anual nessa região está em torno de 24 a $26{ }^{\circ} \mathrm{C}$. Ramos et al. (2006) verificaram que a porcentagem de germinação das sementes de Ochroma pyramidale não foi influenciada pelas temperaturas de 25,30 e $35^{\circ} \mathrm{C}$, porém a velocidade de germinação foi favorecida nas temperaturas de 30 e $35^{\circ} \mathrm{C}$.

Melhores desempenhos germinativos foram verificados também em temperaturas de $30^{\circ} \mathrm{C}$ do que a $20^{\circ} \mathrm{C}$ com diversas espécies arbóreas nativas. Em sementes de Chorisia speciosa, Cavariani e Pinho (1998) observaram que, em temperatura de $20^{\circ} \mathrm{C}$ as sementes germinaram mais lentamente, aumentando em três dias o período de germinação quando comparadas com a temperatura de $30^{\circ} \mathrm{C}$. Mesmo fato ocorreu com sementes de Genipa americana (jenipapo), em que a germinação foi mais rápida a $30{ }^{\circ} \mathrm{C}$ e menor a $20^{\circ} \mathrm{C}$ (ANDRADE et al., 2000).

Sementes de Brosimum gaudichaudii germinaram numa faixa ampla de temperatura $\left(10\right.$ a $\left.45^{\circ} \mathrm{C}\right)$, mas não formaram plântulas nas temperaturas de 10, 15, 40 e $45^{\circ} \mathrm{C}$ (AÑEZ et al., 2002). Resultados semelhantes foram encontrados por Silva et al. (2002) em sementes de Myracrodruon urundeuva (aroeira); nas temperaturas de 10 e $40^{\circ} \mathrm{C}$, a germinação de sementes dessa espécie foi nula, portanto não havendo emissão de raiz nem formação de plântulas normais; o desenvolvimento ocorreu somente numa faixa de 15 a $35^{\circ} \mathrm{C}$.
Em temperaturas mais baixas, o metabolismo da semente é reduzido, podendo germinar em período mais longo (AMARAL e PAULILO, 1992). Redução gradativa de temperatura, em função dos seus efeitos sobre a velocidade de embebição e de mobilização de reservas, provoca decréscimo acentuado na velocidade de germinação (MARCOS FILHO, 2005). Em temperaturas mais elevadas, a velocidade de absorção de água e das reações químicas é maior, e as sementes germinam mais rapidamente (CARVALHO e NAKAGAWA, 2000).

Das sementes que originaram plântulas normais nas temperaturas de 25,30 e $35^{\circ} \mathrm{C}$, o comprimento médio da raiz foi igual a 25 e $30{ }^{\circ} \mathrm{C}(4 \mathrm{~cm})$, diferindo estatisticamente na temperatura de $35{ }^{\circ} \mathrm{C}$, em que o comprimento foi de $3 \mathrm{~cm}$. Quanto ao comprimento da parte aérea, todos os tratamentos diferiram entre si, sendo a maior média obtida na temperatura de $30{ }^{\circ} \mathrm{C}(8,5 \mathrm{~cm})$, seguida das médias de 7,6 e 6,1 $\mathrm{cm}$, respectivamente, nas temperaturas de 35 e $25^{\circ} \mathrm{C}$ (Figura 3 ).

Na Figura 4, pode-se observar que a massa seca das plântulas diferiu estatisticamente em função da temperatura. A massa de matéria seca de plântulas de Parkia pendula foi maior na temperatura de $35^{\circ} \mathrm{C}(0,8017$ g). Nas temperaturas de 30 e $25^{\circ} \mathrm{C}$, as massas foram de 0,7383 e 0,6064 g, respectivamente. A massa seca das plântulas é uma das maneiras de avaliar o crescimento 
da planta, entretanto se pôde verificar que, apesar de maior massa de matéria seca, as plântulas formadas a $35^{\circ} \mathrm{C}$ estavam encurvadas e menores (Figura 2).

A uniformidade e a rapidez da emergência de plântulas são importantes componentes para avaliar o vigor das sementes (NAKAGAWA, 1999). Segundo esse autor, na avaliação do crescimento da plântula, tanto a mensuração do comprimento quanto a determinação da massa seca tornam a análise do vigor da semente mais fácil. A determinação do comprimento de plântula é importante, conjuntamente com o teste de germinação, pois podem ocorrer sementes que apresentam alta porcentagem de germinação e baixo comprimento médio de plântulas, assim como baixa porcentagem de germinação, mas com alto comprimento médio de plântulas.

As sementes de Parkia pendula apresentaram maiores porcentagens de germinação (100\%), de formação de plântulas normais (99\%), maiores comprimentos de raiz $(4 \mathrm{~cm})$ e de parte aérea $(8,5 \mathrm{~cm})$ na temperatura de $30{ }^{\circ} \mathrm{C}$ devido à maior quantidade de água nos tecidos, o que ficou evidenciado pelo maior peso de massa seca à temperatura de $35^{\circ} \mathrm{C}$. As plântulas formadas nessa temperatura tiveram tamanho inferior às encontradas na temperatura de $30^{\circ} \mathrm{C}$, mas apresentaram maior desenvolvimento das raízes secundárias, o que provavelmente ocasionou maior massa do material. Isso pode significar mudança de expressão gênica no sentido de acúmulo de nutrientes resultantes de maior formação de raízes secundárias sob maior estresse hídrico $\left(35^{\circ} \mathrm{C}\right)$, em detrimento de um maior desenvolvimento da parte aérea, sob menor estresse hídrico, como ocorreu a $30{ }^{\circ} \mathrm{C}$.

Alves et al. (2002) usaram a massa seca para concluir que a temperatura de $25^{\circ} \mathrm{C}$ se mostrou mais adequada para condução do teste de germinação e vigor de sementes de Mimosa caesalpiniaefolia, independentemente do substrato, pois a massa seca de plântulas foi maior nessa temperatura. Mas, em Parkia pendula, considera-se que o desenvolvimento da plântula é importante na avaliação do teste de germinação, como se verifica na Figura 2. Dessa forma, o comprimento da plântula e da raiz pode ser usado para se concluir que a temperatura de $30^{\circ} \mathrm{C}$ é a mais adequada para o teste de germinação de sementes dessa espécie.

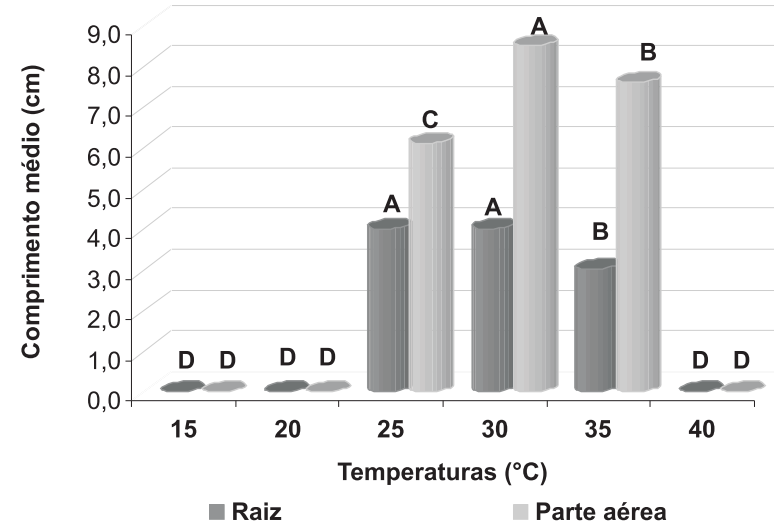

Médias seguidas da mesma letra não diferem entre si, pelo teste de Scott e Knott a $5 \%$ de probabilidade.

Figura 3 - Comprimento de plântulas (cm) de Parkia pendula em diferentes temperaturas.

Figure 3 - Length of Parkia pendula seedlings at different temperatures.

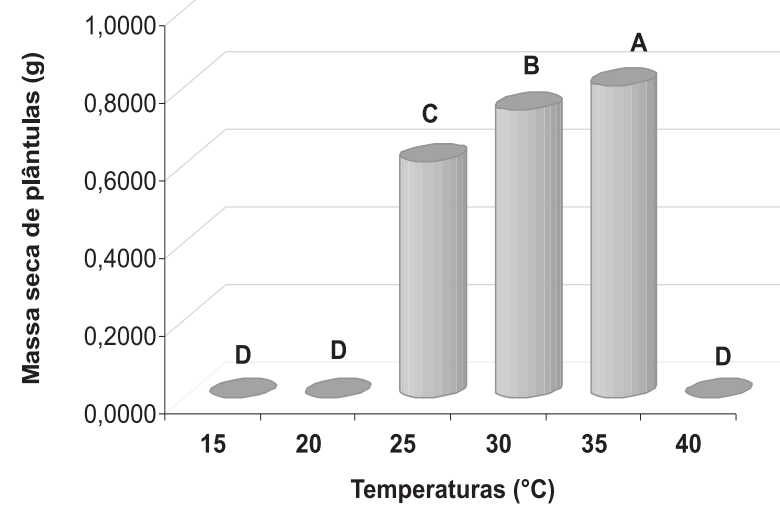

Médias seguidas da mesma letra não diferem entre si, pelo teste de Scott e Knott a $5 \%$ de probabilidade.

Figura 4 - Massa seca de plântulas de Parkia pendula em diferentes temperaturas.

Figure 4-Dry matter of Parkia pendula seedlings at different temperatures.

\section{CONCLUSÕES}

- As sementes de Parkia pendula podem germinar nas temperaturas de $15,20,25,30,35$ e $40{ }^{\circ} \mathrm{C}$, mas a formação de plântulas normais é inibida a 15,20 e $40{ }^{\circ} \mathrm{C}$.

- A temperatura de $30{ }^{\circ} \mathrm{C}$ é considerada a mais favorável para a germinação e formação de plântulas de Parkia pendula.

R. Árvore, Viçosa-MG, v.33, n.1, p.47-55, 2009 


\section{REFERÊNCIAS}

ALVES, E. U. et al. Germinação de sementes de Mimosa caesalpiniaefolia Benth. em diferentes substratos e temperaturas. Revista Brasileira de Sementes, v.24, n.1, p.169-178, 2002.

AMARAL, L. I. V.; PAULILO, M. T. F. Efeito da luz, temperatura, regulador de crescimento e nitrato de potássio na germinação de Miconia cinnamomifolia (DC.) Naudim. Insula, n.21, p.59-86, 1992.

ANDRADE, A. C. S. Germinação de sementes de jenipapo: temperatura, substrato e morfologia do desenvolvimento pós-seminal. Pesquisa Agropecuária Brasileira, v.35, n.3, p.609-615, 2000.

AÑEZ, L. M. M. Temperaturas para germinação de sementes de mama-cadela (Brosimum gaudichaudii Trec - Moraceae). Revista Agricultura Tropical, v.6, n.1, p167-176, 2002

ARAÚJO NETO, J. C. et al. Temperaturas cardeais e efeito da luz na germinação de sementes de mutamba. Revista Brasileira de Engenharia Agrícola e Ambiental, v.6, n.3, p.460-465, 2002.

ARAÚJO NETO, J. C.; AGUIAR, I. B.; FERREIRA, V. M. Efeito da temperatura e da luz na germinação de sementes de Acacia polyphylla DC. Revista Brasileira de Botânica, v.26, n.2, p.249-256, 2003.

BARBOSA, A. P.; VASTANO JÚNIOR, B.; VARELA, V. P. Tratamentos pré-germinativos de sementes de espécies florestais amazônicas II visgueiro (Parkia pendula Benth. Leguminosaemimosoideae). Acta Amazônica, v.14, n.1-2, p.280-288, 1984.

BORGES, E. E. L.; RENA, A. B. Germinação de sementes. In: AGUIAR, I. B.; PIÑA-RODRIGUES, F. C. M.; FIGLIOLIA, M. B. (Coords.). Sementes florestais tropicais. Brasília: ABRATES, 1993. p.83-136.

BRAGA, L. F. et al. Efeito da temperatura na germinação de sementes de purui (Borojoa sorbilis. - Rubiaceae): morfologia das sementes e das plântulas. Revista Brasileira de Sementes, v.21, n.2, p.47-52, 1999.
BRASIL. Ministério da Agricultura e Reforma Agrária. Regras para análise de sementes. Brasília: SNAD/CLAV, 1992. 365p.

CARVAlho, N. M.; NAKAGAWA, J. Sementes: ciência, tecnologia e produção. 4.ed. Jaboticabal: FUNEP, 2000. 588p.

CAVARIANI, C.; PINHO, E. V. R. V. Efeitos da temperatura e do regime de luz na germinação de sementes de paineira (Chorisia speciosa $\mathrm{St}$. Hil.). Informativo ABRATES, v.8, n.1/3, p.23-25, 1998.

LIMA, C. M. R.; BORGHETTI, F.; SOUSA, M. V. Temperature and germination of the Leguminosae Enterolobium contortisiliquum. Revista Brasileira de Fisiologia Vegetal, v.9, n.2, p.97-102, 1997.

LIMA, J. D. et al. Efeito da temperatura e do substrato na germinação de sementes de Caesalpinia ferrea Mart. ex Tul. (Leguminosae, Caesalpinoideae). Revista Árvore, v.30, n.4, p.513-518, 2006.

LORENZI, H. Árvores brasileiras: manual de identificação e cultura de espécies arbóreas do Brasil. 3.ed. Nova Odessa: Plantarum, 2000. v.1.368p.

LOUREIRO, A. A. et al. Essências madeireiras da Amazônia. Manaus: MCT/ INPA-CPPF, 2000. v.4. 191p.

MARCOS FILHO, J. Fisiologia de sementes de plantas cultivadas. Piracicaba: FEALQ, 2005. 495p.

MIRANDA, P. R. M.; FERRAZ, I. D. K. Efeito da temperatura na germinação de sementes e morfologia da plântula de Maquira sclerophylla (Ducke) C.C. Berg. Revista Brasileira de Botânica, v.22, n.2, p.303-307, 1999.

NAKAGAWA, J. Testes de vigor baseados no desempenho das plântulas. In: KRZYZANOWSKI, F. C.; VIEIRA, R. D.; FRANÇA NETO, J. B. (Eds). Vigor de sementes: conceitos e testes. Londrina: ABRATES, 1999. p.2.1-2.24.

NASCIMENTO, W. M. O. et al. Temperatura e substrato para germinação de sementes de Parkia platycephala Benth. (Leguminosae-Mimosoideae). Revista Agricultura Tropical, v.7, n.1, p.119-129, 2003. 
OLIVEIRA, L. M. et al. Temperatura e regime de luz na germinação de sementes de Tabebuia impetiginosa (Martius ex A.P. de Candolle) Standley e T. serratifolia Vahl Nich. Bignoniaceae. Ciência e Agrotecnologia, v.29, n.3, p.642-648, 2005.

RAMOS, M. B. P.; VARELA, V. P.; MELO, M. F. F. Influência da temperatura e da quantidade de água no substrato sobre a germinação de sementes de Ochroma pyramidale (Cav. ex Lam.) Urban (pau-de-balsa). Acta Amazônica, v.36, n.1, p.103-106, 2006.

SCHIMDT, L. Guide to handling of tropical and subtropical forest seed. Denmark: Danida Forest Seed Centree, 2000. 511p.

SILVA, L. M. M.; RODRIGUES, T. J. D.; AGUIAR, I. B. Efeito da luz e da temperatura na germinação de sementes de aroeira (Myracrodruon urundeuva Allemão). Revista Árvore, v.26, n.6, p.691-697, 2002.
SOUZA, M. H.; MAGLIANO, M. M.; CAMARGOS, J. A. A. Madeiras tropicais brasileiras. Brasília: IBAMA/LPF, 1997. 157p.

SOUSA-SILVA, J. C. et al. Germinação de sementes e emergência de plântulas de espécies arbóreas e arbustivas que ocorrem em matas de galeria. In: RIBEIRO, J. F.; FONSECA, C. E. L.; SOUSA-SILVA, J. C. $($ Eds). Cerrado: caracterização e recuperação de matas de galeria. Planaltina: Embrapa Cerrados, 2001. p.379-422.

TOLEDO, F. F.; MARCOS FILHO, J. Manual das sementes: tecnologia da produção. São Paulo: Agronômica Ceres, 1977. 224p.

VARELA, V. P.; FERRAZ, I. D. K.; CARNEIRO, N. B. Efeito da temperatura na germinação de sementes de sumaúma (Ceiba pentandra (L.) Gaertn. - Bombacaceae). Revista Brasileira de Sementes, v.21, n.2, p.170-174, 1999. 